\title{
Compact CPW-fed bow-tie and triangle slotted antenna with wide impedance bandwidth characteristics
}

\author{
Mohammad Mahdi Shafiei ${ }^{1}$, Wan Nor Liza Mahadi ${ }^{2,}{ }^{*}$, Mahmoud Moghavvemi $^{3}$ \\ ${ }^{1}$ Department of Electrical Engineering, Faculty of Engineering, University of Malaya (UM), 50603 Kuala Lumpur, Malaysia \\ ${ }^{2}$ ElectroMagnetic Radiation and Devices Research Group (EMRD), Department of Electrical Engineering, Faculty of Engineering, \\ University of Malaya (UM), 50603 Kuala Lumpur, Malaysia \\ ${ }^{3}$ Center of Research in Applied Electronics (CRAE), Department of Electrical Engineering, Faculty of Engineering, University of \\ Malaya (UM), 50603 Kuala Lumpur, Malaysia
}

\section{A R T I C L E I N F O}

Article history:

Received 9 August 2016

Received in revised form

17 September 2016

Accepted 8 October 2016

Keywords:

Compact antenna

Wideband antenna

Bow-tie

CPW-fed

Loaded stub

\section{Introduction}

Printed microstrip slot antennas have been used in many wireless communication systems because of their small size, low profile, light weight, low cost and simplicity of the structure, installation and fabrication (Moosazadeh and Kharkovsky, 2014; Sung, 2012; Luo et al., 2013). These types of antennas easily can integrate with monolithic microwave integrated circuits (MMICs) and provide stable radiation patterns (Lin et al., 2013; Volakis et al., 2010). On the other hand, patch antennas are known that they have narrow bandwidth. According to the literature, varieties of methods have been used to improve the bandwidth of patch antennas such as gap coupling (Kandwal and Khah, 2013), using an asymmetric dual-branch feed (Liu et al., 2013), embedding types of slots (Chao-Ming et al., 2012; Shafiei et al., 2015; Shafiei and Roslee, 2009), using parasitic structures inside the slot (Ojaroudi and Ojaroudi, 2013), magnetic ground plane (Yang et al., 2013) and parasitic patches (Fan et al., 2012).

Therefore by using a proper geometry for the antenna structure, large bandwidth is achievable

\footnotetext{
* Corresponding Author.

Email Address: wnliza@um.edu.my (W. N. L. Mahadi)

https://doi.org/10.21833/ijaas.2016.10.004

2313-626X/C) 2016 The Authors. Published by IASE.

This is an open access article under the CC BY-NC-ND license

(http://creativecommons.org/licenses/by-nc-nd/4.0/)
}

(Azim et al., 2013). One of the wideband antenna geometries that they have reported in many publications are the bow-Tie antenna. In addition, the type of feeding is an effective feature for bandwidth characteristics of the antenna. Indeed there are some reported Bow-Tie antennas that they have fed by coaxial line (Daotie and Jun-Fa, 2012; Shi-Wei, 2013; Shi-Wei et al., 2008), coplanar waveguide (Hadarig et al., 2010; Wusheng et al., 2013) and stripline (Hao et al., 2013; Sayidmarie and Fadhel, 2013).

The Bow-Tie antenna has been used in many applications such as imaging (Yurduseven et al., 2013), ground penetrating radars (Faraji et al., 2009), WiFi access (Kaswiati and Suryana, 2012), and pulse antennas (Lestari et al., 2004). In addition, it satisfies our requirements for having a low profile antenna with large bandwidth characteristics, high radiation efficiency and ease of fabrication.

Simple structure antenna can be realized by means of microstrip line feeding structure or coplanar waveguide (CPW) feeding structure (Mandal and Das, 2013). This feeding structure next to the single sided printed antenna provides an easy means of fabrication and installation for the antenna. CPW feeding structure facilitates matching and gain improvements by easy parallel and series connections. CPW-fed printed slot antenna provides easy means of integration with Monolithic Microwave Integrated Circuits (MMICs) (Simons, 2001; Smith et al., 2013) in addition to its 
advantages for demonstrating the wider bandwidth as well as less radiation loss and less dispersion (Eldek et al., 2004; Mandal and Das, 2013).

In this paper, a CPW-fed antenna is presented which consists of two slots; Bow-Tie and triangle. Inside the Bow-Tie slot a stub and load have embedded. The antenna prototype is built on a single side of a printed circuit board (PCB) and directly matched to the $50 \Omega$ SMA connector.

The antenna is carefully analysed in terms of the reflection coefficients, voltage standing wave ratio (VSWR) and Radiation pattern in working frequency band. The analysis and assessment of the antenna is performed by means of the CST Microwave StudioTM. The measurement results of the proposed antenna prove the validity of our simulations.

\section{Antenna design and fabrication}

CPW-Fed loaded stub is embedded inside a BowTie slot area and there is a triangle slot on top of that to comply with our desired performance and characteristics. Alignment is a problem during fabrication of the double sided printed antennas. The problem can be solved by having the structure on one side of the substrate. The CPW-Fed is such a feeding line that can provide a single sided structure. This feeding type provides lower loss in comparison with the microstrip line feed. The proposed geometry is shown in Fig. 1. The parametric design of the antenna provides more degrees of freedom for tuning purposes during simulation to achieve proper results (Fig. 2).

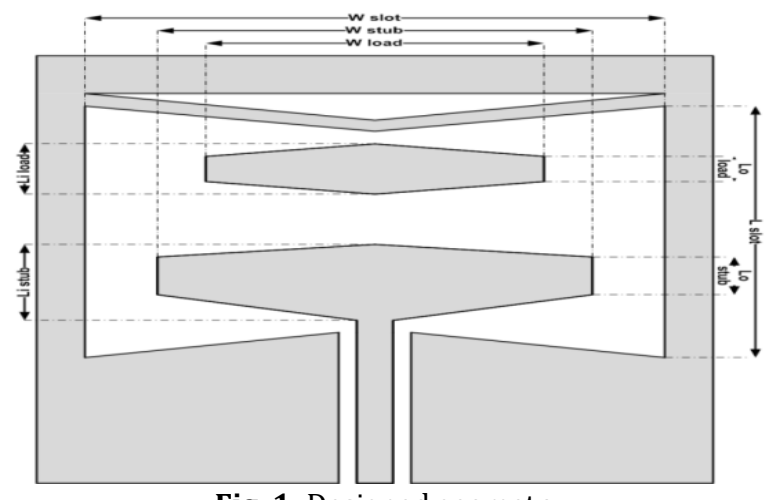

Fig. 1: Designed geometry

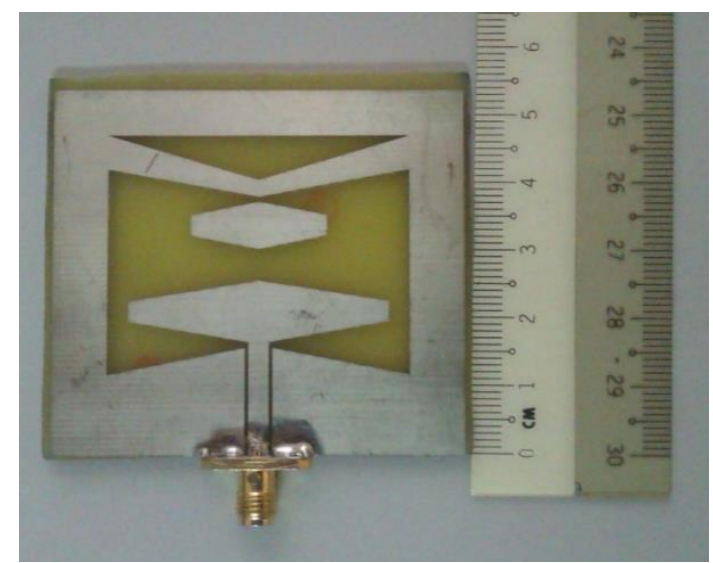

Fig. 1: Fabricated antenna
The dimensions of the antenna have been formed by variables that define the size and geometry of the antenna. The fabricated values are as follows: (All sizes are in millimetre)

$\begin{array}{ll}\text { Wslot: } 44 & \text { Wstub: } 32 \quad \text { Wload: } 20 \\ \text { Lslot: } 32 & \text { Listub: } 8 \text { Liload: } 7 \\ \text { Lostub: } 4 & \text { Loload: } 3\end{array}$

The proposed antenna has only one side fabrication which makes the antenna easier for fabrication and integration. Fig. 1 presents the fabricated antenna. For the fabrication board we used copper coated FR4 material. The relative permittivity ( $\mathrm{\varepsilon r}$ ) of the fibre is 4.3 and it has $1.6 \mathrm{~mm}$ thickness.

\section{Results and discussion}

\subsection{Return loss}

One of the most important characteristics of the antenna is return loss. Fig. 2 presents reflection coefficient for the designed antenna in both simulation and measurement. The reflection coefficient of the feed port expresses the amount of return loss happened due to the port mismatch. As long as the $\mathrm{S} 11$ is lower than $-10 \mathrm{~dB}$ line, the return loss is acceptable and it determines the working frequency band of the antenna. The measurement presents lower bandwidth than simulation but it still covers our desired frequency band from $1.7 \mathrm{GHz}$ to $2.6 \mathrm{GHz}$.

\subsection{VSWR}

Reflection coefficient can express voltage standing wave ratio (VSWR). The simulation and measurement results for the VSWR demonstrated in Fig. 3. It describes the power reflected from the antenna input port.

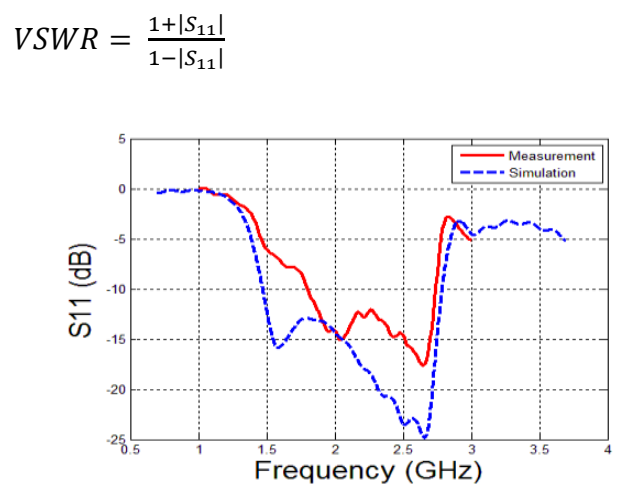

Fig. 2: Return loss - measurement VS simulation

\subsection{Radiation pattern}

The free space E-plane and H-plane radiation pattern have been measured for frequencies of $1420 \mathrm{MHz}, 1500 \mathrm{MHz}, 2100 \mathrm{MHz}$ and $2600 \mathrm{MHz}$ and shown in Fig. 4, Fig. 5, Fig. 6 and Fig. 7 respectively. 
The solid line and the dash line are co-polarized and cross-polarized components, respectively.

It was expected to have smaller amplitudes at $1420 \mathrm{MHz}$ and $1500 \mathrm{MHz}$, because the higher amplitude for the radiation pattern is expected when the VSWR is less than 2.1. Indeed, the better performance for the radiation pattern is achievable at lower VSWR.

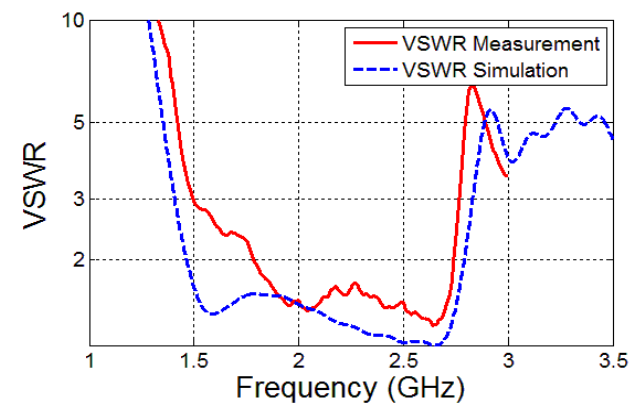

Fig. 3: VSWR - measurement VS simulation

It can be observed from the radiation pattern graphs that the antenna exhibits approximately omni-directional radiation patterns for $\mathrm{H}$-plane. Because the wavelength is much larger than the antenna size at working frequencies, the radiation pattern in E-plane is nearly close to symmetrical.

The electrical length of the antenna increases at higher frequencies but the some asymmetry shapes in the radiation pattern happens by the CPW feeding structure. At higher resonant frequencies this effect becomes less than lower resonant frequencies. When the frequency increases, higher order harmonic introduces to patterns and consequently the pattern shapes become more directional. The measured radiation patterns of the antenna are similar to those of a typical monopole antenna.
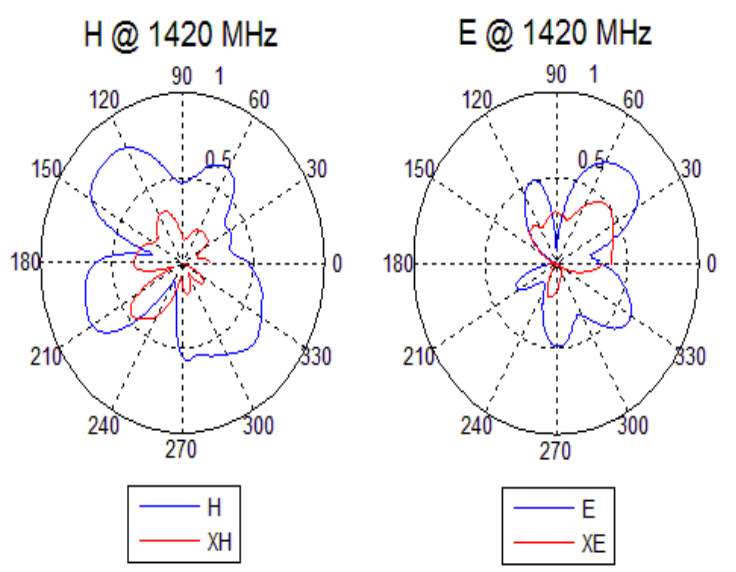

Fig. 4: Radiation pattern @ $1420 \mathrm{MHz}$

\section{Conclusions}

The paper proposed a CPW-Fed printed antenna width a Bow-Tie and a triangle slot. The stub and the load are embedded inside the Bow-Tie slot area and all together provide a single sided planar geometry. The designed antenna provides more than 50\% bandwidth around the center frequency of $2.15 \mathrm{GHz}$. The frequency band is from $1.7 \mathrm{GHz}$ to $2.6 \mathrm{GHz}$.
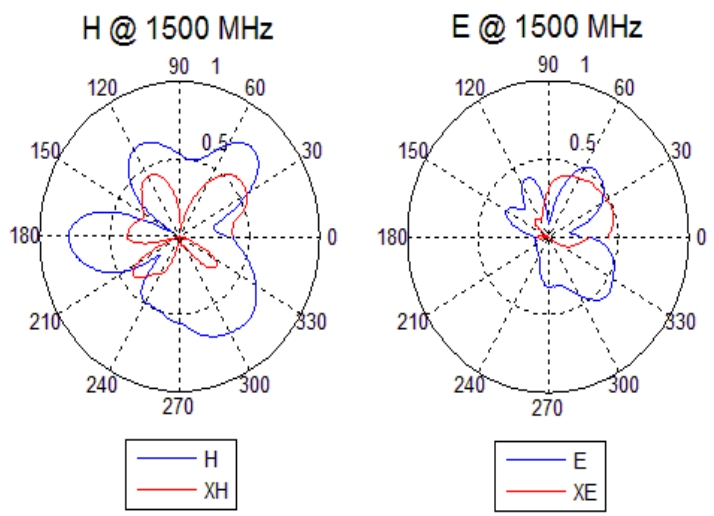

Fig. 5: Radiation pattern @ $1500 \mathrm{MHz}$
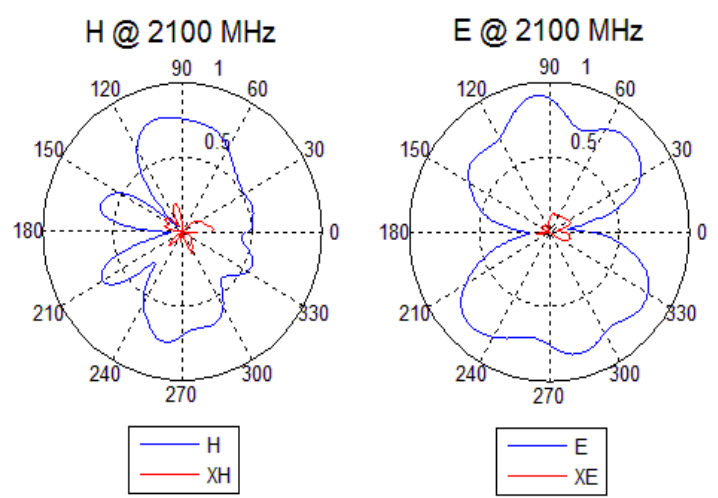

Fig. 6: Radiation pattern @ $2100 \mathrm{MHz}$

CPW-Fed structure provides wider bandwidth with lower dispersion in comparison with Probe-Fed and Microstrip Line-Fed antennas. This characteristic is desired for many applications. Unipolar configuration of the single sided CPW-Fed antenna is easy to be implemented. Also fabrication and integration of this structure is easy. This kind of printed antenna complies with the requirement of small size and light weight, so it is very useful for portable systems. Because of using FR4 substrate and simple structure the antenna is very low cost. Bow-Tie geometry provides radiation characteristics similar to rectangle antenna, but smaller size. The results are proven through simulation, fabrication and measurement.

\section{Acknowledgment}

Acknowledgement to University of Malaya for PPP funding under Grant Number PG092-2012B.
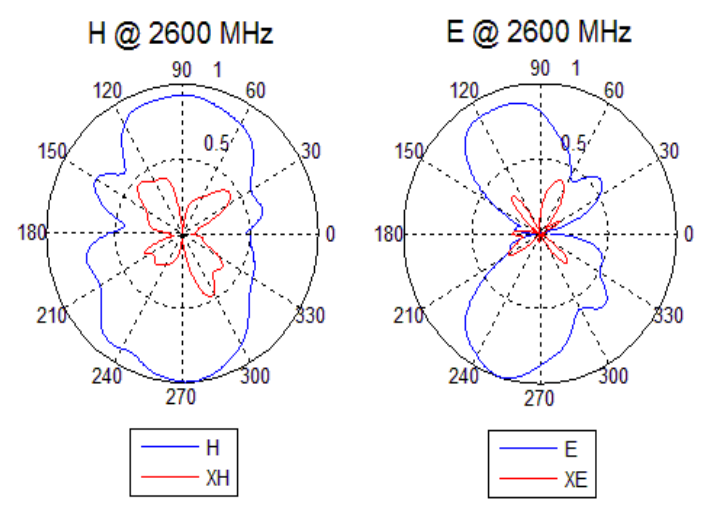

Fig. 7: Radiation pattern @ $2600 \mathrm{MHz}$ 


\section{References}

Azim R, Islam M and Misran N (2013). Printed circular disc compact planar antenna for UWB applications. Telecommunication Systems, 52(2): 1171-1177.

Chao-Ming W, Yung-Lun C and Wen-Chung L (2012). A compact ultrawideband slotted patch antenna for wireless USB dongle application. IEEE Antennas and Wireless Propagation Letters, 11: 596-599.

Daotie L and Jun-Fa M (2012). A koch-like sided fractal bow-tie dipole antenna. IEEE Transactions on Antennas and Propagation, 60(5): 2242-2251.

Eldek AA, Elsherbeni AZ and Smith CE (2004). Characteristics of bow-tie slot antenna with tapered tuning stubs for wideband operation. Progress In Electromagnetics Research, PIER, 49: 53-69.

Fan ST, Yin YZ, Lee B, Hu W, and Yang X (2012). Bandwidth enhancement of a printed slot antenna with a pair of parasitic patches. IEEE Antennas and Wireless Propagation Letters, 11: 1230-1233.

Faraji HS, Moini R, Sadeghi SHH and Talebi HA (2009). Design of a new wire bow-tie antenna for ultrawide-band GPR applications using multiobjective genetic algorithm. 13 ${ }^{\text {th }}$ IEEE International Symposium on Antenna Technology and Applied Electromagnetics and the Canadian Radio Science Meeting (ANTEM/URSI 2009). https://doi.org/10.1109/ANTEMURSI.2009.4805 110

Hadarig RC, De Cos Gomez ME, Alvarez Y and LasHeras F (2010). Novel bow-tie-AMC combination for 5.8-GHz RFID tags usable with metallic objects. IEEE Antennas and Wireless Propagation Letters, 9: 1217-1220.

Hao W, Yan C, Fangshu L and Xiaowei S (2013). Wideband and compact quasi-Yagi antenna with bowtie-shaped drivers. Electronics Letters, 49(20): 1262-1264.

Kandwal A and Khah SK (2013). A novel design of gap-coupled sectoral patch antenna. IEEE Antennas and Wireless Propagation Letters, 12: 674-677.

Kaswiati WS and Suryana J (2012). Design and realization of planar bow-tie dipole array antenna with dual-polarization at $2.4 \mathrm{GHz}$ frequency for Wi-Fi access point application. $7^{\text {th }}$ IEEE International Conference on the Telecommunication Systems, Services, and Applications (TSSA). https:// doi.org/ 10.1109/ TSSA.2012.6366055

Lestari AA, Yarovoy AG and Ligthart LP (2004). RCloaded bow-tie antenna for improved pulse radiation. IEEE Transactions on Antennas and Propagation, 52(10): 2555-2563.

Lin Z, Kye-Yak S, Bing Z and Zhang YP (2013). Integration of dual-band monopole and microstrip grid array for single-chip tri-band application. IEEE Transactions on Antennas and Propagation, 61(1): 439-443.

Liu J, Esselle KP, Hay SG and Zhong SS (2013). Compact super-wideband asymmetric monopole antenna with dual-branch feed for bandwidth enhancement. Electronics Letters, 49(8): 515516.

Luo YL, Xu L, Xin ZY and He S (2013). A compact CPW-fed UWB antenna with GSM, GPS, Bluetooth and dual notch bands applications. Progress in Electromagnetics Research C, 35: 205-219.

Mandal T and Das S (2013). An optimal design of CPW-fed UWB aperture antennas with wimax/WLAN notched band characteristics. Progress In Electromagnetics Research C, 35: 161-175.

Moosazadeh M and Kharkovsky S (2014). Compact and small planar monopole antenna with symmetrical L- and U-shaped slots for WLAN/WiMAX applications. IEEE Antennas and Wireless Propagation Letters, 13: 388-391.

Ojaroudi N and Ojaroudi M (2013). Novel design of dual band-notched monopole antenna with bandwidth enhancement for UWB applications. IEEE Antennas and Wireless propagation letters, 12: 698-701.

Sayidmarie KH and Fadhel YA (2013). A planar selfcomplementary BOW-Tie antenna for UWB applications. Progress In Electromagnetics Research C, 35: 253-267.

Shafiei MM and Roslee M (2009). A compact slotted bowtie patch antenna. The 2009 International Symposium on Antennas and Propagation (ISAP 2009), Bangkok, Thailand.

Shafiei MM, Moghavvemi M and Mahadi WNL (2015). Antenna tackles Wi-Fi and WiMAX. Microwaves and RF, 63, pp.80-83.

Shi-Wei Q (2013). Millimeter-wave cavity-backed antenna array with high gain and simple structure. The IEEE International Wireless Symposium (IWS), https://doi.org/ 10.1109/ IEEE-IWS.2013.6616715

Shi-Wei Q, Jia-Lin L and Quan X (2008). High-gain wideband leaky-wave antenna excited by bowtie element. IEEE Transactions on Antennas and Propagation, 56(8): 2469-2474.

Simons R (2001). Coplanar waveguide circuits, components, and systems. John Wiley, New York, USA.

Smith SL, Merkle T, Smart KW, Hay SG, Mei S and Ceccato F (2013). Design aspects of an antenna- 
mmic interface using a stacked patch at 71-86 GHz. IEEE Transactions on Antennas and Propagation, 61(4): 1591-1598.

Sung Y (2012). Bandwidth enhancement of a microstrip line-fed printed wide-slot antenna with a parasitic center patch. IEEE Transactions on Antennas and Propagation, 60(4): 1712-1716.

Volakis JL, Chen CC and Fujimoto K (2010). Small antennas: miniaturization techniques and applications. McGraw-Hill, New York, USA.

Wusheng J, Ge L, Dongsheng Y and Hong G (2013). Analysis and study of CPW-fed bow-tie-slotcoupled antenna. The IEEE Fifth International
Conference on Computational and Information Sciences (ICCIS): 1111-1113. https://doi.org/ 10.1109/ICCIS.2013.295

Yang W, Wang H, Che W and Wang J (2013). A wideband and high-gain edge-fed patch antenna and array using artificial magnetic conductor structures. IEEE Antennas and Wireless Propagation Letters, 12: 769-772.

Yurduseven O, Smith D and Elsdon M (2013). Printed slot loaded bow-tie antenna with super wideband radiation characteristics for imaging applications. IEEE Transactions on Antennas and Propagation, 61(12): 6206-6210. 